\title{
Effect of Flunarizine on Arterial Thrombosis after Endarterectomy in Rats
}

\author{
Hidenori Kobayashi, Minoru HaYASHI, Hirokazu KaWANO, \\ Yuji HANDA, Masanori KABUTO and Shinjiro KOBAYASHI* \\ Department of Neurosurgery, Fukui Medical School, Fukui; *Department of Chemical \\ Pharmacology, Toyama Medical and Pharmaceutical University, Toyama
}

\begin{abstract}
Unilateral carotid endarterectomy was performed microsurgically in 60 rats. The effects of perioperative administration of aspirin and flunarizine, a $\mathrm{Ca}^{2+}$ entry blocker, on thrombus formation were examined 24 hours after endarterectomy. An untreated group of endarterectomized rats served as controls. Platelet adhesion, blood cells, and fibrin cords were observed at the cut edge of the intima as well as in the endarterectomized area in all three groups. However, these findings were significantly more extensive in the control group than in the drug-treated groups. Flunarizine was as effective as aspirin in inhibiting platelet adhesion and fibrin cord formation. Both drugs significantly increased the patency rate after carotid endarterectomy.
\end{abstract}

Key words: carotid endarterectomy, flunarizine, aspirin

\section{Introduction}

Carotid endarterectomy is now generally accepted as a useful procedure for the prevention of major stroke in patients with ischemic symptoms whose angiograms demonstrate significant atheromatous plaque at the ipsilateral common carotid artery bifurcation. However, major postoperative complications occur in $1.1-21.1 \%$ of patients; ${ }^{7}$ the complication rate varies greatly depending on the institutes reported in the literature. Two of the most dangerous complications of carotid endarterectomy are acute postoperative occlusion and recurrent stenosis. In the hope of finding ways to prevent these complications, much experimentation has been conducted in rabbits, ${ }^{10)}$ dogs, ${ }^{5,6)}$ cats, ${ }^{14)}$ and, more recently, rats. ${ }^{16)}$

Loss of endothelium or exposure of the collagen of the media after carotid endarterectomy leads to rapid activation of platelets and may subsequently cause thrombus formation. ${ }^{10,12)}$ Aspirin's antithrombotic effect involves suppression of thromboxane $A_{2}$ production through inhibition of platelet cyclo-oxygenase. ${ }^{15)} \mathrm{Ca}^{2+}$ entry blockers, such as flunarizine, protect the endothelial lining against the des-

Received August 15, 1988; Accepted February 14, 1989 quamating effect of citrate and inhibit stimulation of platelet aggregation by epinephrine and arachidonic acid. ${ }^{11,13)}$

We compared the effects of flunarizine and aspirin on thrombus formation following microsurgical carotid endarterectomy in rats.

\section{Materials and Methods}

Sixty male Wistar rats weighing 200-250 gm were randomized into a control group $(\mathrm{n}=20$ ), a flunarizinetreated group $(n=20)$, and an aspirin-treated group $(n=20)$. Each group received three intraperitoneal injections 1 hour before, immediately after, and 12 hours after endarterectomy. The controls were given saline, and the experimental rats received $1.5 \mathrm{mg} / \mathrm{kg}$ flunarizine or $3 \mathrm{mg} / \mathrm{kg}$ aspirin.

Carotid endarterectomy was performed under 40 $\mathrm{mg} / \mathrm{kg}$ sodium pentobarbital, injected intraperitoneally. An anterior skin incision was made from shoulder to shoulder. The right common carotid artery was exposed and temporarily occluded with two polyethylene vascular occluders. A longitudinal incision of approximately $8 \mathrm{~mm}$ in length was made in the artery under an operating microscope. The intimal surface was cut transversely in two locations $4 \mathrm{~mm}$ apart with the tip of a 27-gauge needle, 


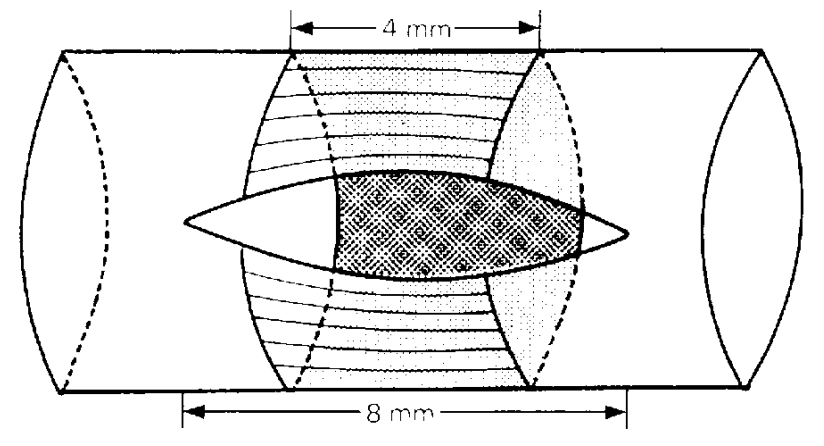

Fig. 1 Diagrammatic illustration of the endarterectomy procedure. A longitudinal incision $8 \mathrm{~mm}$ in length was made in the anterior wall of the common carotid artery. The endarterectomized segment was $4 \mathrm{~mm}$ in length.

after which the intervening intima and a portion of the media were excised circumferentially with the tips of microforceps (Fig. 1). The vessel was then closed with 10-0 monofilament nylon suture and the vascular occluders were removed.

All animals were sacrificed 24 hours after surgery. The cardiovascular system was perfused with $30 \mathrm{ml}$ of saline followed by $30 \mathrm{ml}$ of $2.5 \%$ glutaraldehyde buffered with $0.1 \mathrm{M}$ sodium cacodylate. The perfusion pressure was maintained at $100 \mathrm{~cm} \mathrm{H}_{2} \mathrm{O}$. The common carotid artery was excised and divided into two pieces, one of which was prepared for scanning electron microscopy (SEM) and one for transmission electron microscopy (TEM). The SEM specimens were stored in cacodylate-buffered $2.5 \%$ glutaraldehyde for 2 hours and postfixed in $1 \%$ osmium tetroxide in the same buffer for 1 hour at $4^{\circ} \mathrm{C}$. They were dehydrated in graded alcohols and amyl acetate, critical point dried with $\mathrm{CO}_{2}$, coated with gold in an evaporator (EIKO 1B-3), and examined with a Hitachi S-450 SEM. The TEM specimens were fixed and dehydrated in the same manner, then embedded in Epon 812. Semi-thin sections were cut with an LKB ultramicrotome and stained with toluidine blue. Ultra-thin sections were cut from selected areas and stained with uranyl acetate and lead citrate and examined with a Hitachi H-600 TEM. The data concerning patency versus occlusion were analyzed by the Chi-square test between the control group and the drug-treated groups.

\section{Results}

Table 1 shows the patency rates after carotid endarterectomy, which were $60 \%$ in the control group, $100 \%$ in the flunarizine-treated group, and $95 \%$ in
Table 1 Patency rates in control and drug-treated endarterectomized rats

\begin{tabular}{ccc}
\hline Control & $\begin{array}{c}\text { Flunarizine- } \\
\text { treated }\end{array}$ & $\begin{array}{c}\text { Aspirin- } \\
\text { treated }\end{array}$ \\
\hline $12 / 20(60 \%)$ & $20 / 20(100 \%)^{*}$ & $19 / 20(95 \%)^{* *}$ \\
\hline${ }^{*} \mathrm{p}<0.01,{ }^{* *} \mathrm{p}<0.05$ versus control (Chi-square test).
\end{tabular}

the aspirin-treated group. Both the flunarizine- and aspirin-treated groups exhibited significantly greater patency than did the controls.

Histological examination of the vessels disclosed adhesion of platelets, erythrocytes, and leukocytes to the endarterectomized sites. Compared to no treatment, flunarizine and aspirin administration both reduced the number of platelets attached to the luminal surface. Figure 2 is a SEM specimen of the distal end of the endarterectomized segment in a flunarizine-treated rat. Adhesion of platelets and erythrocytes is particularly evident at the cut edge of the intima. Figures 3 and 4 show sutured sites in animals of the flunarizine- and aspirin-treated groups, respectively. Adherent platelets, erythrocytes, and fibrin cords were observed on the nylon suture as well as in the endarterectomized area. In the control group, thrombosed vessels were filled with fibrin cords and blood cells (Fig. 5). Figure 6, TEM specimens from flunarizine-treated rats, show a thrombus at the endarterectomized site. Endothelial cells near the site displayed indentations on the basement membrane side and contained many cytoplasmic vesicles. Leukocytes were found in the endarterectomized region and were also observed in the junctions between and beneath endothelia. These changes were seen in all three groups.

\section{Discussion}

Following endarterectomy, platelets adhered to the operated site, including its periphery, and to the exposed suture material. Maximum adhesion of fibrin, platelets, and erythrocytes was observed at the periphery, which was rolled. The degree of endothelial damage resulting from endarterectomy varies according to the proximity of endothelium to the operated site and the surgical technique. ${ }^{5)}$ In our study, the endothelial cells had indentations of different sizes on the basement membrane side and many cytoplasmic vesicles. Leukocytes migrated between and beneath endothelial layers. The leukocytes may cause desquamation of the endothelial cells. 

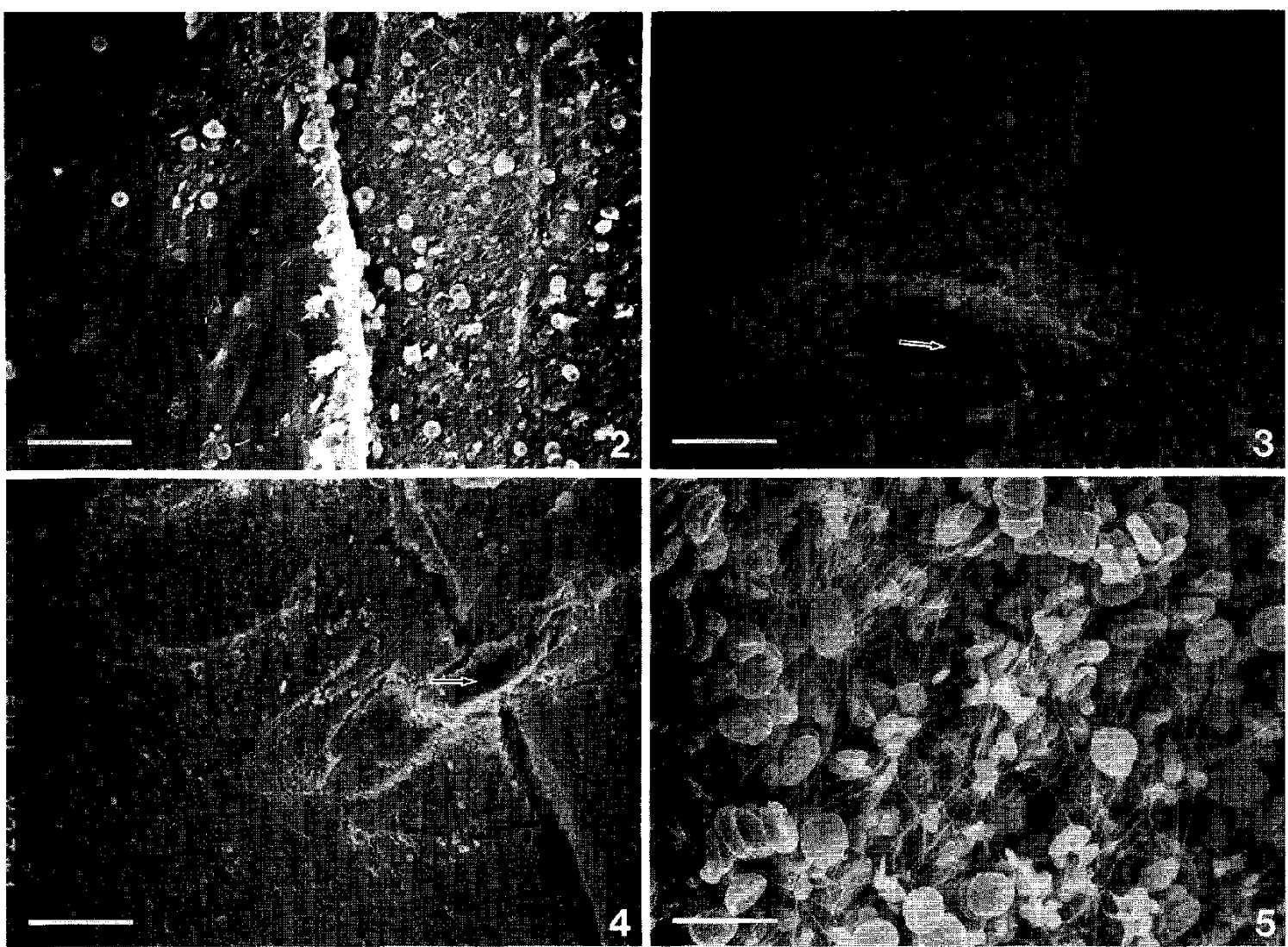

Fig. 2 SEM specimen of the distal end of the endarterectomized segment in a flunarizine-treated rat. Adhesion of platelets and erythrocytes is seen at the cut edge of the intima and endarterectomized area. $B a r=50 \mu \mathrm{m}$.

Fig. 3 SEM specimen of the sutured site in a flunarizine-treated rat. A fibrin-platelet layer is observed on the nylon suture (arrow) as well as in the endarterectomized area. Bar $=50 \mu \mathrm{m}$.

Fig. 4 SEM specimen of the sutured site in an aspirin-treated rat. Endothelial damage due to the suture (arrow) is seen in the non-endarterectomized area. Bar $=100 \mu \mathrm{m}$.

Fig. 5 SEM specimen from a control rat, showing fibrin cords and blood cells in a thrombosed vessel. Bar $=15 \mu \mathrm{m}$.
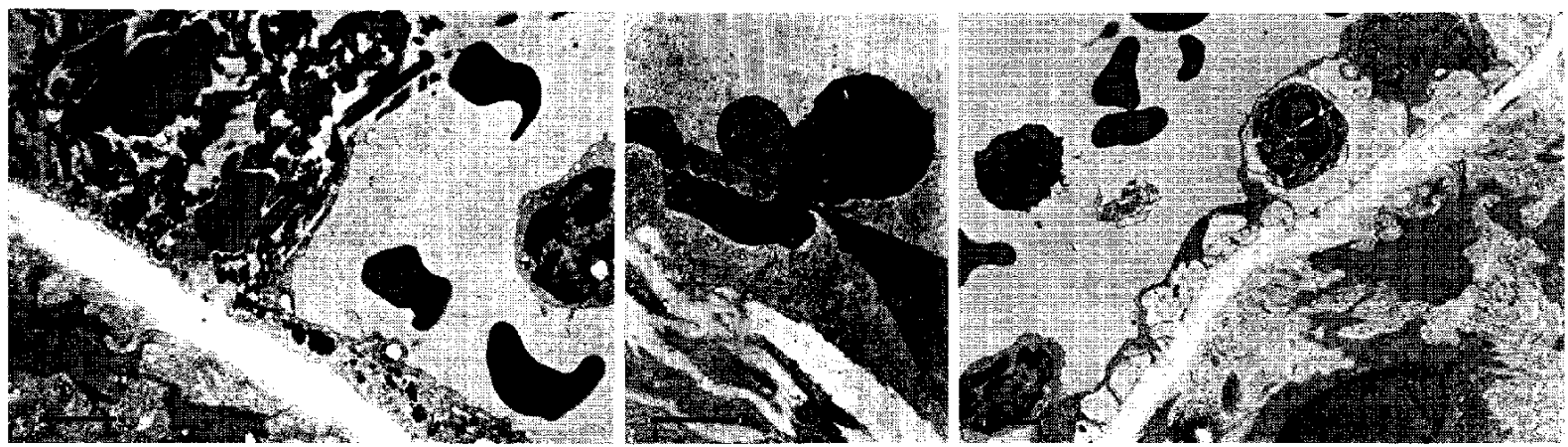

Fig. 6 TEM specimens from flunarizine-treated rats. left: A thrombus is seen in the endarterectomized site. center: A leukocyte is present in the junction between two endothelia near the endarterectomized site. right: Endothelial cells are indented on the basement membrane side and contain many cytoplasmic vesicles. A leukocyte is seen beneath an endothelial layer. Bar $=5$ $\mu \mathrm{m}$. 
Platelets are known to play an important role in the initiation and propagation of arterial thrombus formation. ${ }^{18)}$ Perioperative administration of aspirin or other antiplatelet drugs has been shown to significantly reduce thrombus formation after vascular surgery. ${ }^{1-3,8)}$ Ercius et al. ${ }^{6}$ found that $10 \mathrm{mg} / \mathrm{kg}$ aspirin, given to dogs 18 hours before carotid endarterectomy, significantly reduced thrombus formation at the endarterectomy site. However, there have been no reports concerning the effect of flunarizine on thrombus formation.

The production of thromboxane $\mathrm{A}_{2}\left(\mathrm{TXA}_{2}\right)$ by platelets and the synthesis of prostacyclin $\left(\mathrm{PGI}_{2}\right)$ by the vessel wall are both important in the regulation of hemostasis and thrombosis. ${ }^{9,19)} \mathrm{TXA}_{2}$ is a potent platelet aggregator and vasoconstrictor, whereas $\mathbf{P G I}_{2}$ inhibits platelet aggregation and promotes vasodilatation. Aspirin blocks the production of these two important prostaglandins by inhibiting cyclo-oxygenase (an enzyme common to the synthesis of both) ${ }^{15)}$ Cyclo-oxygenase within platelets appears to be more sensitive to this inhibition than that within the vessel wall. ${ }^{2,9)}$ Aspirin, although effective, causes gastrointestinal bleeding when given in high doses. ${ }^{17)}$

Flunarizine, a selective $\mathrm{Ca}^{2+}$ entry blocker, was shown to suppress contractions of vascular smooth muscle and protect against loss of functional deformability of erythrocytes. ${ }^{4)}$ Oral pretreatment of animals with flunarizine resulted in significant protection of the endothelial lining against the desquamating effect of citrate. ${ }^{11)}$ Our results showed that flunarizine was as effective as aspirin in decreasing the rate of thrombosis after carotid endarterectomy. Sasaki et $a l .{ }^{16)}$ reported that all endarterectomized vessels in both control and those rats treated with heparin or $\mathrm{TXA}_{2}$ synthetase inhibitor were patent 7 days after operation, without apparent mural thrombus formation. However, we observed thrombi in our drug-treated groups as well as in the control group. We used rats weighing 200-250 gm, whereas Sasaki and coworkers used 400 - to 450 -gm rats. This may have affected the results, since the smaller the animal, the more difficult the surgical procedure itself is. Also, Sasaki et al. washed the endarterectomy lumen with heparinized saline, which we did not do. These may account for the differences in the arterial patency rate between our control group and their controls after endarterectomy.

In conclusion, endothelial and medial damage adjacent to the endarterectomized site is one of the major causes of endarterectomy failure. Our results indicate that perioperative flunarizine or aspirin treatment can reduce the incidence of this complication.

\section{References}

1) Bannister CM, Chapman SA: The influence of systemic aspirin on rat small diameter vein graft: $A$ scanning electron microscopic study. Surg Neurol 13: 99-108, 1980

2) Boysen B, Bottcher J, Olsen JS: Minimum daily dosage of ASA for platelet inhibition. Stroke 13: 721, 1982

3) Canadian Cooperative Stroke Study Group: A randomized trial of aspirin and sulfinpyrazone in threatened stroke. $N$ Engl J Med 299: 53-59, 1978

4) De Cree J, De Cock W, Geukens H, De Clerck F, Beerens M, Verhaegen $\mathrm{H}$ : The rheological effects of cinnarizine and flunarizine in normal and pathological conditions. Angiology 31: 505-515, 1979

5) Dirrenberger RA, Deen GH Jr, Sundt TM Jr: Temporal profile of the healing process following endarterectomy, in Sundt TM Jr (ed): Occlusive Cerebrovascular Disease: Diagnosis and Surgical Management. Philadelphia, WB Saunders, 1987, pp 232-242

6) Ercius MS, Chandler WF, Ford JW, Swanson DP, Burke JC: Effect of different aspirin doses on arterial thrombosis after canine carotid endarterectomy: A scanning electron microscope and indium-111-labeled platelet study. Neurosurgery 14: 198-203, 1984

7) Ferguson GG: Extracranial carotid artery surgery. Clin Neurosurg 29: 543-574, 1982

8) Findlay JM, Lougheed WM, Gentili F, Walker PM, Glynn MFX, Houle S: Effect of perioperative platelet inhibition on postcarotid endarterectomy mural thrombus formation. Results of a prospective randomized controlled trial using aspirin and dipyridamole in humans. $J$ Neurosurg 63: 693-698, 1985

9) Hanley SP, Bevan I, Cockbill SR, Heptinstall S: Differential inhibition by low-dose aspirin of human venous prostacyclin synthesis and platelet thromboxane synthesis. Lancet 1: 969-970, 1981

10) Hattori $A$, Watanabe $T$, Izumi $T$ : Scanning electron microscope study on hemostatic reaction: Mural thrombus after the removal of endothelium, with special references to platelet behavior, site of fibrin formation and microhemolysis. Arch Histol Jpn 41: 205-227, 1978

11) Hladovec J, De Clerck F: Protection by flunarizine against endothelial cell injury in vivo. Angiology 32: 448-462, 1981

12) Kobayashi $H$, Hayashi $M$, Kawano $H$, Handa $Y$, Kabuto M, Shirasaki N: Ultrastructural and immunohistochemical findings after microsurgical vein graft on the carotid artery of the rat, in Gagliardi R, Benvenuti L (eds): Controversies in EIAB for Cerebral Ischemia. Bologna, Monduzzi Editore, 1987, pp 723-730

13) Okamutsu S, Peck RC, Lefer AM: Effects of calcium channel blockers on arachidonate-induced sudden death in rabbits. Proc Soc Exp Biol Med 166: 551- 
555,1981

14) Piepgras DG, Sundt TM Jr, Didisheim P: Effect of anticoagulants and inhibitors of platelet aggregation on thrombotic occlusion of endarterectomized cat carotid arteries. Stroke 7: 248-254, 1976

15) Roth GJ, Majerus PW: The mechanism of the effect of aspirin on human platelets: I. Acetylation of a particulate fraction protein. $J$ Clin Invest 56: 624-632, 1975

16) Sasaki T, Kassell NF, Turner DM, Yamashita $M$, Spallone A: Microsurgical carotid endarterectomy in rats. Neurosurgery 15: 683-689, 1984

17) Swedish Cooperative Study Group: High-dose acetylsalicylic acid after cerebral infarction. Stroke
18: 325-334, 1987

18) Weiss HJ: Platelet physiology and abnormalities of platelet function. First of two parts. $N \mathrm{Engl} \mathrm{J} \mathrm{Med}$ 293: 531-541, 1975

19) Weiss HJ, Turitto VT: Prostacyclin (prostaglandin $I_{2}$, $\mathrm{PGI}_{2}$ ) inhibits platelet adhesion and thrombus formation on subendothelium. Blood 53: 244-250, 1979

Address reprint requests to: H. Kobayashi, M.D., Department of Neurosurgery, Fukui Medical School, 23 Shimoaizuki, Matsuoka-machi, Yoshida-gun, Fukui 910-11, Japan. 